\title{
Requirements for interconnection of HVDC links with DC-DC converters
}

\author{
Daniel Gómez A. \\ SuperGrid Institute \\ Villeurbanne, France \\ https://orcid.org/0000-0002- \\ 5647-0488 \\ Piotr Dworakowski \\ SuperGrid Institute \\ Villeurbanne, France \\ https://orcid.org/0000-0002- \\ 6893-0103
}

\author{
Juan D. Páez \\ SuperGrid Institute \\ Villeurbanne, France \\ https://orcid.org/0000-0002- \\ 8712-3630 \\ Oriol Gomis-Bellmunt \\ CITCEA-UPC \\ Barcelona, Spain \\ https://orcid.org/0000-0002- \\ 9507-8278
}

\author{
Marc Cheah-Mane \\ CITCEA-UPC \\ Barcelona, Spain \\ https://orcid.org/0000-0002- \\ 0942-661X \\ Florent Morel \\ SuperGrid Institute \\ Villeurbanne, France \\ https://orcid.org/0000-0003- \\ 3098-7806
}

\author{
Jose Maneiro \\ SuperGrid Institute \\ Villeurbanne, France \\ https://orcid.org/0000-0002- \\ $5717-6176$
}

\begin{abstract}
The number of high voltage direct current (HVDC) links continue to increase over the years, most of them, for offshore applications or bulk power transmission over long distances. The present paper evaluates the possible development of a direct current (dc) grid in Europe given the present, and future, HVDC links. Eight potential cases for the interconnection between close links are suggested as starting scenario for a multiterminal network. The need of a dc-dc converter and its special requirements are evaluated in function of suggested interconnections. As an example, a case study is chosen to evaluate the behavior of an interconnection between line commutated converter (LCC) and voltage source converter (VSC) link using a front-to-front (F2F) isolated converter.
\end{abstract}

Keywords- HVDC offshore grid, dc-dc converter, HVDC transmission, Modular Multilevel Converter (MMC), Line Commutated converter (LCC).

\section{INTRODUCTION}

High voltage direct current (HVDC) links have been taking place in the electrical transmission system for bulk power transmission over long distances, due to the absence of reactive power consumption on the line [1], low electrical losses and lower environmental impact related with the right of way (ROW) [2]. Thanks to these benefits, a HVDC link can reduce the cost of a long line, compared to the high voltage alternate current (HVAC) link, after the called "break-even-distance".

The main use of HVDC links, in Europe, is for offshore applications, where the benefits of HVDC cables overcome those of the HVAC. This can be evidenced in Fig.1 and 2 [3] with the number of HVDC lines installed and projected on the North Sea. The development of the HVDC technologies has opened the discussion for possible dc grid applications [4], [5]. Particular challenges have been identified such as the interoperability, the system stability, the resilience, the fault management and the power flow control [6]. Dc-dc converters are the elements that can help to solve the challenges increasing the controllability of the dc grid [7]

For the development of future dc grids, two possible options may arise, either it is planned in advance, or it uses the already installed equipment to reduce the costs (case studied in this

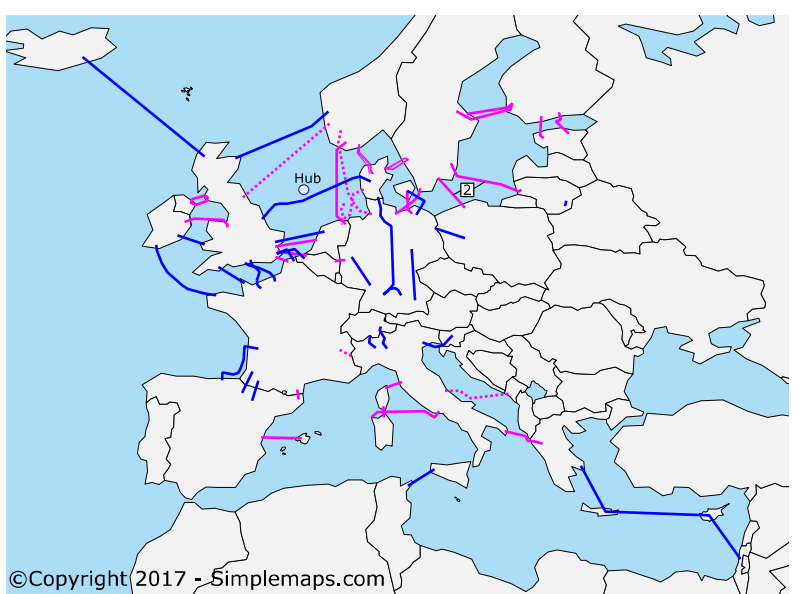

Fig. 1. HVDC already installed links (magenta), the dashed lines are those in construction. Future projects (blue) in Europe including the North Sea Power Hub and potential interconnection 2 (Table I).

paper). The main inconvenient with this last scenario is the incapacity to interconnect two HVDC links of different characteristics without the use of an intermediary component (dc-dc converter) as the links have not been designed for multiterminal operation. The links may have different voltage levels, power rating, technology used, grounding, etc. Therefore, a dc-dc converter is needed for the interconnection of different already installed HVDC links.

The development of the dc grid is uncertain, but the role of the dc-dc converters has been already identified for the future multiterminal dc systems [7]. This paper suggests possible applications for dc-dc converters in Europe (Section II) as initial scenarios of multiterminal dc systems. The applications are evaluated in function of the current situation of the HVDC links [8] and the future projects in Europe [9], [10]. Even though these scenarios may not be realistic (missing detailed assessment), they can be used as a representative sample of the possible European dc grid and evaluate the requirements for the dc-dc converters. Section II details the identified requirements for the $\mathrm{dc}-\mathrm{dc}$ converters depending on the suggested applications. Section IV, shows simulation results for a case study chosen to represent the general converter requirements. 
TABLE I. POTENTIAL INTERCONNECTIONS GIVEN THE CURRENT HVDC INSTALLATIONS

\begin{tabular}{|c|c|c|c|c|c|c|c|}
\hline $\begin{array}{c}\text { Potential } \\
\text { interconnection }\end{array}$ & Link 1 & Link 2 & $\begin{array}{c}\text { Voltage } \\
\text { ratio }\end{array}$ & Technology & $\begin{array}{c}\text { Topology } \\
\text { (grounding) }\end{array}$ & $\begin{array}{c}\text { Countries } \\
\text { /TSO }\end{array}$ & Comments \\
\hline 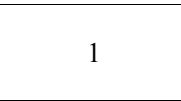 & $\begin{array}{c}\text { Baltic Cable 450kV - } \\
\text { 600MW } \\
\text { (Sweden - Germany) }\end{array}$ & $\begin{array}{c}\text { Kontek 400kV - } \\
\text { 600MW } \\
\text { (Germany - Denmark) }\end{array}$ & 1.13 & LCC - LCC & $\begin{array}{l}\text { Asymmetric } \\
\text { monopole } \\
\text { (both lines) }\end{array}$ & 3 & $\begin{array}{l}\text { Crossing point } \\
\text { available }\end{array}$ \\
\hline 2 & $\begin{array}{c}\text { SwePol 450kV - } \\
\text { 600MW } \\
\text { (Sweden - Poland) }\end{array}$ & $\begin{array}{c}\text { NordBalt 300kV - } \\
\text { 700MW } \\
\text { (Sweden - Lithuania) }\end{array}$ & 1.5 & LCC-VSC & $\begin{array}{l}\text { Asymmetric } \\
\text { monopole - } \\
\text { Bipole }\end{array}$ & 3 & $\begin{array}{l}\text { No crossing } \\
\text { point. }\end{array}$ \\
\hline
\end{tabular}

TABLE II. POTENTIAL INTERCONNECTIONS INCLUDING FUTURE HVDC PROJECTS

\begin{tabular}{|c|c|c|c|c|c|c|c|}
\hline $\begin{array}{c}\text { Potential } \\
\text { interconnection }\end{array}$ & Link 1 & Link 2 & $\begin{array}{c}\text { Voltage } \\
\text { ratio }\end{array}$ & Technology & $\begin{array}{c}\text { Topology } \\
\text { (grounding) }\end{array}$ & $\begin{array}{l}\text { Countries } \\
\text { /TSO }\end{array}$ & Comments \\
\hline 3 & $\begin{array}{c}\text { COBRA Cable } \\
\pm 320 \mathrm{kV}-700 \mathrm{MW} \\
\text { (Netherlands - } \\
\text { Denmark) }\end{array}$ & $\begin{array}{c}\text { NordLink 525kV - } \\
\text { 1400MW } \\
\text { (Germany - Norway) }\end{array}$ & 1.64 & VSC - VSC & $\begin{array}{l}\text { Symmetric } \\
\text { monopole - } \\
\text { Rigid Bipole }\end{array}$ & 4 & $\begin{array}{l}\text { Crossing point } \\
\text { available }\end{array}$ \\
\hline 4 & $\begin{array}{c}\text { NordLink 525kV - } \\
\text { 1400MW } \\
\text { (Germany - Norway) }\end{array}$ & $\begin{array}{l}\text { Viking link 400-500kV } \\
-1000-1400 \mathrm{MW} \\
\text { (Denmark - UK) }\end{array}$ & $1.31-1.05$ & VSC - VSC & $\begin{array}{c}\text { Rigid Bipole - } \\
\text { Bipole }\end{array}$ & 4 & $\begin{array}{l}\text { Crossing point } \\
\text { available }\end{array}$ \\
\hline 5 & $\begin{array}{l}\text { Viking link 400- } \\
500 \mathrm{kV}-1000- \\
\text { 1400MW } \\
\text { (Denmark - UK) }\end{array}$ & $\begin{array}{c}\text { NorNed } 450 \mathrm{kV} \text { - } \\
\text { 700MW } \\
\text { (Norway - Netherlands) }\end{array}$ & $\begin{array}{l}1.11- \\
1.13\end{array}$ & VSC - LCC & $\begin{array}{l}\text { Bipole - } \\
\text { Symmetric } \\
\text { monopole }\end{array}$ & 4 & $\begin{array}{l}\text { Crossing point } \\
\text { available }\end{array}$ \\
\hline 6 & $\begin{array}{l}\text { Nemo Link 400kV - } \\
\text { 1000MW (Belgium - } \\
\text { UK) }\end{array}$ & $\begin{array}{c}\text { BritNed 450kV - } \\
\text { 1000MW } \\
\text { (UK - Netherlands) }\end{array}$ & 1.13 & VSC - LCC & $\begin{array}{l}\text { Symmetric } \\
\text { monopole - } \\
\text { Bipole }\end{array}$ & 3 & $\begin{array}{l}\text { No crossing } \\
\text { point }\end{array}$ \\
\hline 7 & $\begin{array}{c}\text { SuedLink } 2000 \mathrm{MW} \\
\text { (Germany) }\end{array}$ & $\begin{array}{l}\text { SuedOstLink } \geqslant 2000 \\
\text { MW (Germany) }\end{array}$ & Unknown & Unknown & Unknown & 3 & $\begin{array}{l}\text { No crossing } \\
\text { point. }\end{array}$ \\
\hline 8 & $\begin{array}{c}\text { Ultranet } 380 \mathrm{kV} \\
2000 \mathrm{MW} \text { (Germany) }\end{array}$ & $\begin{array}{c}\text { SuedLink } 2000 \text { MW } \\
\text { (Germany) }\end{array}$ & Unknown & $\begin{array}{c}\text { VSC - } \\
\text { Unknown }\end{array}$ & Unknown & 2 & $\begin{array}{c}\text { No crossing } \\
\text { point. }\end{array}$ \\
\hline 9 & $\begin{array}{r}\text { Viking }-\mathrm{No} \\
\text { (UK- Denmark- } \\
\text { Netl }\end{array}$ & $\begin{array}{l}\text { Link - NorNed } \\
\text { Yermany -Norway - } \\
\text { rlands) }\end{array}$ & $\begin{array}{c}1.05- \\
1.31\end{array}$ & $\begin{array}{c}\text { VSC - LCC } \\
\text {-VSC }\end{array}$ & $\begin{array}{c}\text { Bipole }- \text { Rigid } \\
\text { Bipole - } \\
\text { Symmetric } \\
\text { monopole }\end{array}$ & 5 & $\begin{array}{l}\text { Two crossing } \\
\text { points available } \\
\text { for } 2 \mathrm{dc}-\mathrm{dc} \\
\text { converters }\end{array}$ \\
\hline
\end{tabular}

\section{APPLICATIONS}

Currently, the transmission grid in Europe has 18 point-topoint links (P2P) IGBT-based, Voltage Source Converter (VSC) [11], 20 P2P links thyristor-based [12], Line Commutated Converter (LCC) and one link using both technologies in parallel (Skagerrak).

Based on Fig. 1, eight suggested dc-dc interconnections are presented in Table I and II. The interconnections were chosen by the lines proximity and number of countries and/or Transmission System Operators (TSOs) interconnected, assuming that the interconnection of different markets can be beneficial for the involved parties. Under these assumptions, two close links, interconnecting the same two countries and/or TSOs, are less interesting interconnection to assess because it would not increase the interconnected markets. Other evaluation criteria could lead to different conclusions e.g. a political analysis as the one presented in [13], a detail evaluation studied in the PROMOTioN project [14], or an optimization approach in [15]. In general, a cost-benefit analysis [16] evaluates the complete project impact in detail, but it is beyond the scope of this paper.

\section{A. Existing HVDC links}

Assuming the already installed links, 2 potential cases can be identified for the use of a dc-dc converter, presented in Table I. The first case is the intersection of the Baltic cable (GermanySweden) and the Kontek line (Germany-Denmark) shown in

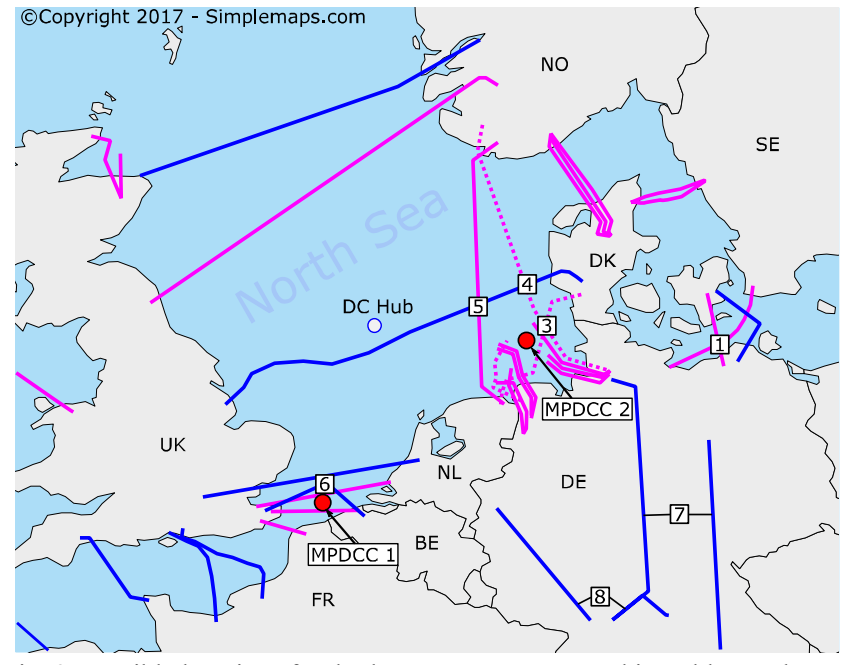

Fig. 2. Possible locations for dc-dc converters suggested in Table I and II and the dc Hub in the North Sea. Multiport de converter (MPDCC) 1 (red circle) interconnecting UK-France-Nederland and Belgium. MPDCC 2, interconnecting Germany-Nederland-Denmark and possibly Norway.

Fig. 2. The use of a dc-dc converter to interconnect both lines can increase the number of countries or transmission system operators (TSO) interconnected from 2, on each line, to 3 (Germany-Sweden-Denmark). In the second example, SwePol (Sweden-Poland)-NordBalt (Sweden-Lithuania), the cables do not cross each other, but their proximity makes the connection 
possible with extra cable segments (Fig. 1). The installation of the extra cables is feasible considering the repairing techniques known to date [17], [18].

\section{B. Future interconnections}

Including projects under construction and future HVDC links (Fig. 2, blue lines), six main examples for HVDC interconnection have been identified in Table II.

The potential interconnection 3, connects the lines under construction, Cobra Cable and NordLink. This dc-dc converter can increase the power flow between Netherlands, Denmark, Germany and Norway. The links have a crossing point to install the dc converter without the need of a cable extension. For the potential converters 4 and 5 (Table II), the interconnections Viking Link - NordLink and Viking Link - NorNed are suggested. As it is noticeable in Fig. 2, Viking Link, interconnecting UK-Denmark, cross the NorNed and NordLink creating a possible application for the $\mathrm{dc}-\mathrm{dc}$ converter installation. If the two crossing points are used for the installation of dc-dc converters, the total interconnected system will have five countries as a dc multiterminal scheme around Viking Link (potential interconnection 9). The last 3 suggested interconnections $(6,7$ and 8$)$ do not have a crossing point to install the dc-dc converter but their proximity can increase the power flow in their respective zones. Suggested interconnection 6 can increase the interaction between UK-Belgium and Netherlands while potential interconnections 7 and 8, can increase the power flow flexibility inside Germany interconnecting the four TSO's market zones.

Fig. 2, presents the North Sea power hub [19], [20], a project presented to interconnect windfarms with Denmark, Germany and Netherlands. It will have a gradually increasing capacity up to $12 \mathrm{GW}$ and it could be the first real implementation of a dc multiterminal system in the European region. Based on the North Sea power hub project, other locations for multiport dc converters (MPDCC) could be available for the interconnections between the windfarms and/or the neighboring countries. Fig. 2, shows the suggested locations for MPDCC 1 and 2. The MPDCC 1 is rather to interconnect the countries around, due to their proximity (UK-France-Belgium-Netherlands). This MPDCC 1, will, probably, need to adapt different dc voltages and grid topologies (in function of the projects on the region). MPDCC 2 shows a location close to the already installed HVDC lines for the windfarms in the north of Germany and it could help interconnect the four neighboring countries (GermanyNetherlands-Denmark-Norway). In this case, if the MPDCC 2 is used to interconnect the near windfarms, the required converter need to adapt medium voltage ratios [6] (up to 1.9), different technologies and grid topologies (bipole, rigid bipole [21], symmetric monopole, asymmetric monopole). MPDCC are a possible option to interconnect the growing HVDC installations in the North Sea, but they are subject to more diverse requirements, more detailed evaluation must be done on this subject.

\section{REQUIREMENTS FOR THE DC-DC CONVERTERS}

Table I and II present the technical characteristics of the dc suggested interconnections, including the voltage ratio, the technology and the grid topology (grounding strategy) of each link. The following subsections explain why two HVDC links having a difference in, at least, one of these parameters require a dc-dc converter for their interconnection. Additional possible requirements, for the dc-dc converter, are included in the discussion.

\section{A. Voltage ratio}

Two dc systems with different voltage ratings cannot be interconnected without a dc-dc converter. This converter must adapt the voltage difference and ensure the security of the interconnected systems (e.g. high voltage should not appear on the low voltage side). The isolation requirements can increase with the relation between voltages, called voltage ratio.

The voltage ratio is the relation between the voltage level of the links to be interconnected $\left(\mathrm{V}_{\mathrm{DC} 1} / \mathrm{V}_{\mathrm{DC} 2}\right)$. Following the classification presented in [6], only 2 of the presented examples (Tables I and II) have a medium voltage ratio $(\geq 1.5)$. These are: SwePol - NordBalt (1.5) and COBRA Cable-NordLink (1.64). The rest of the examples lay within a small voltage ratio $(\leq 1.5)$. The interconnection of small voltage ratio can be made with less constraints, with respect to the medium/high voltage ratio, as the interconnection might not need galvanic isolation [6].

\section{B. Technologies interconnection}

The interconnection of different HVDC technologies is present in half of the examples. These interconnections can be interesting in the future of the European dc grid as HVDC links are (almost) evenly distributed between LCC and VSC. The main characteristics of each HVDC technology, important for their interconnection, are listed below.

The use of thyristors valves, in the LCC converters, force the dc current in a single direction, therefore the reversal power flow is made by changing the voltage in the HVDC line. In case of transients on the inverter ac side, LCC is susceptible to commutation failures, equivalent to a short circuit on the dc side. The LCC line can reverse the dc voltage to extinguish the arc, subject to a dc fault, thus, this technology can work in a P2P, using overhead lines, without the installation of dc circuit breakers (DCCB).

On the contrary, VSC uses IGBTs (with a diode in antiparallel), maintaining the voltage polarity unchanged. The power flow reversal is achieved by changing the current direction. The dc faults are cleared with ac circuit breakers, DCCB or full bridge submodules (FBSM) depending on the system stability, and/or protection, requirements.

For the interconnection of different technologies, [6] suggests the use of a dc-dc converter with galvanic isolation, mainly for the commutation failures (equivalent to a dc fault) and the power reversal in LCC links (voltage polarity inversion).

\section{P2P topology}

The third technical parameter compared on Tables I and II, is the grounding strategy (topology). This is the most fluctuating parameter on the suggested cases. The P2P topology is a parameter in function of the needs and restrictions of each project. A bipole structure can be chosen to increase the availability after a dc fault, but to reduce the cost, the metallic return can be omitted to create a rigid bipole or a symmetrical monopole, reducing also the system availability. From this 
perspective, the link topology is not a parameter that can be standardized easily. Consequently, the future interconnections will, most likely, take care of this special requirement.

Two different grid topologies may have different transients during a given DC fault. E.g., a pole to ground fault in a bipole cable, may have a small impact in the healthy pole and the system can continue with partial operation after the fault. On the contrary, the same fault in a symmetric monopole can increase the voltage, in the healthy cable, up to 2 p.u. and loss the power flow capability until the equipment is repaired. These differences can increase the requirements for a dc-dc converter interconnecting different topologies, e.g. a degraded mode for faults on the bipole side and overvoltage capability in the symmetric monopole side.

\section{Additional requirements}

The dc-dc converter requirements may change in function of the application. A complete evaluation of the converter requirements is beyond the scope of this paper. Some additional requirements are listed below.

Depending on the system control and protection strategy, different specifications for the dc-dc converter may be required. In function of the grid control strategy, the converter can be asked to work in power, voltage or droop control. This requirement may change for different grid operation points. The grid protection strategy can define the fault and post faults requirements of the converter. As it was mentioned in the previous subsection, the grid topology may change the transient behavior during a fault and also the possible system reconfiguration after the contingence.

The dc-dc converter can increase the power availability after a fault in a line. A system reconfiguration is possible, isolating the faulty side. The new system needs to optimize its operation in function of the system losses and the converter, lines and power ratings of healthy stations. This post-fault scenario may influence the design of the dc-dc converter specifying its power rating and degraded mode requirements.

General requirements of the converter must be taken into account, i.e., the capacity to isolate perturbations to keep system security and the need of galvanic isolation [6]. The complete specifications may lead to an already exiting solution. The proper converter topology for each application can be evaluated based on the state of the art compiled in the literature [7], [22][24]

\section{CASE STUdy}

In this section, a general scenario is proposed to represent each dc-dc converter requirements compared in the previous section (voltage ratio, technology and topology). The dc voltages are $800 \mathrm{kV} / 500 \mathrm{kV}$ equivalent to a medium voltage ratio (1.6), similar to suggested interconnection 2 and 3 in Table I and II. The HVDC technologies being interconnected are LCC and VSC, modular multilevel converter (MMC), as interconnections 2, 5 and 6. The topologies are: a symmetric monopole (MMC link) and an asymmetric monopole (LCC link), shown in Fig. 3.

The MMC link is a symmetric monopole $\pm 400 \mathrm{kV}, 1 \mathrm{GVA}$, with a total cable length of $200 \mathrm{~km}$. The cable was simulated

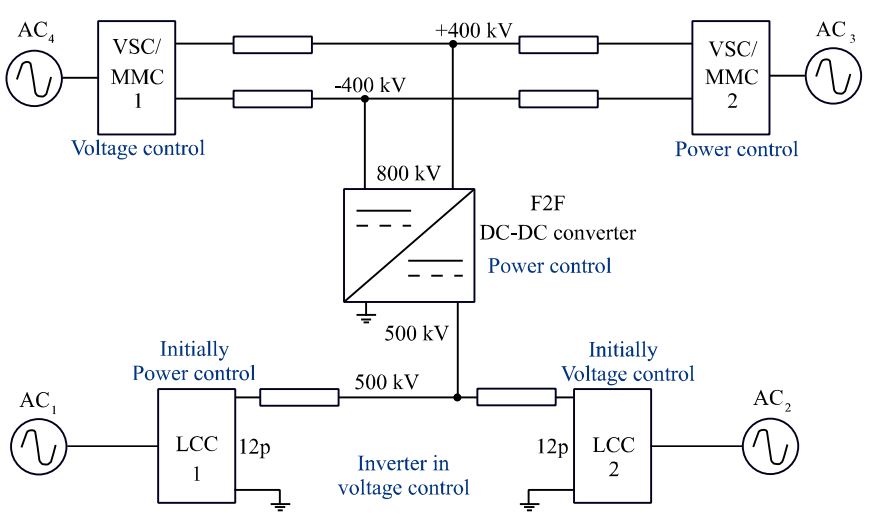

Fig. 3. System studied. MMC line (top), LCC line (bottom), interconnection using a F2F dc-dc converter isolated (middle).

with a wideband model from the Best paths project [25]. For simplicity, $\mathrm{MMC}_{1}$ and $\mathrm{MMC}_{2}$ are identical, as well as their respective ac systems (400 $\left.\mathrm{kV}_{\mathrm{RMS}} \mathrm{L}-\mathrm{L}\right) . \mathrm{MMC}_{1}$ is set to control voltage and $\mathrm{MMC}_{2}$ is controlling power.

The LCC link, is an asymmetrical monopole of 12 pulses, $500 \mathrm{kV}$ dc, 1 GVA, based on the Cigré HVDC benchmark, where the cable was simulated as a $\mathrm{T}$ model (series resistance, inductance and a capacitor to ground). The details of the cable, ac impedances and ac filters can be found in [26]. The general parameters for each link are listed in Table III, the parameters are presented for the total length of $200 \mathrm{~km}$ in the case of the MMC link.

As the case study includes medium voltage ratio (1.6), different HVDC technology and different topology; following the recommendations from [6], the dc-dc converter should have galvanic isolation. The MMC Front-to-front (F2F) is chosen, as it is a well-known converter in the literature that fulfill the requirements for this application. Fig. 4, shows the F2F in detail including half bridge submodules (HBSM) on the MMC link side and FBSM on the LCC side. The need of the FBSM is due to the voltage polarity change for the power reversal in LCC links. Switchgear is not considered in this paper, where the cables are mechanically disconnected and reconnected to keep the voltage polarity on the dc-dc converter while the LCC line voltage has been inverted, in that case HBSM can be implemented on the LCC side. The F2F converter is connected in the middle of both HVDC links as shown in Fig. 3. The general parameters of the F2F converter are presented in Table IV.

TABLE III. PARAMETERS DC-DC CONVERTER

\begin{tabular}{|l|c|c|}
\hline \multicolumn{1}{|c|}{ Parameter } & $\begin{array}{c}\text { High Voltage } \\
\text { side (MMC) }\end{array}$ & $\begin{array}{c}\text { Low Voltage } \\
\text { side (LCC) }\end{array}$ \\
\hline AC frequency & \multicolumn{2}{|c|}{$150 \mathrm{~Hz}$} \\
\hline $\begin{array}{l}\text { AC impedance (R, L) referred } \\
\text { to High voltage side }\end{array}$ & \multicolumn{2}{|c|}{$80 \mathrm{~m} \Omega, 40 \mathrm{mH}$} \\
\hline Tranformer voltage ratio & $800 \mathrm{kV} \Delta / \mathrm{Y} 500 \mathrm{kV}$ \\
\hline Arm resistance & $1 \Omega$ & $0.626 \Omega$ \\
\hline Arm inductance & $50 \mathrm{mH}$ & $39 \mathrm{mH}$ \\
\hline Capacitance per SM (Fig. 4) & $3 \mathrm{mF}$ & $4.5 \mathrm{mF}$ \\
\hline Number of submodules per arm & 500 & 313 \\
\hline Equivalent capacitance (Fig. 5) & $6 \mu \mathrm{F}$ & $14.4 \mu \mathrm{F}$ \\
\hline
\end{tabular}

The case study was implemented in Matlab-Simulink with a detailed LCC model and an arm average model for the MMC converters [27] shown in Fig. 5. The F2F converter using FBSM 


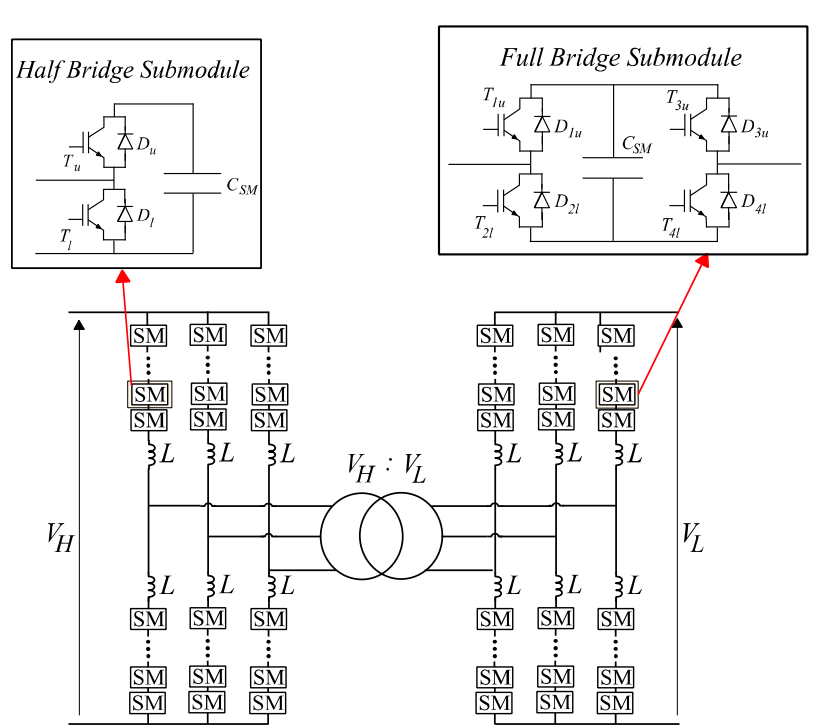

Fig. 4. dc-dc converter (MMC F2F) used for the case study. The high voltage side (MMC link) has HBSM while the low voltage side (LCC link) has FBSM.

was implemented with the arm average model presented in [28]. More detailed models can be used to validate the control strategy or make fault simulations, but it is not the scope of this paper. The MMC (including the dc-dc converter) stations are controlled with an energy-based strategy presented in [29], [30]. The general energy control approach can be found in [31]. The LCC is controlled based on the strategy presented in [32], keeping the inverter station in voltage control mode [33]. The power flow through the dc-dc converter is limited to $300 \mathrm{MW}$ due to stability issues discussed in [34].

TABLE IV. PARAMETERS LINES AND CONVERTER STATIONS

\begin{tabular}{|l|c|c|}
\hline \multicolumn{1}{|c|}{ Parameter } & Link 1 (MMC) & Link 2 (LCC) \\
\hline Total cable resistance & $1.1 \Omega$ & $5 \Omega$ \\
\hline Total cable inductance & $600 \mathrm{mH}$ & $0.2 \mathrm{H}$ \\
\hline Total cable capacitance & $48.4 \mu \mathrm{F}$ & $26 \mu \mathrm{F}$ \\
\hline AC frequency & $50 \mathrm{~Hz}$ & $50 \mathrm{~Hz}$ \\
\hline AC impedance $(\mathrm{R}, \mathrm{L})$ & $80 \mathrm{~m} \Omega, 0.5 \mathrm{mH}$ & $\sim 3.7 \Omega, \sim 151 \mathrm{mH}$ \\
\hline Arm resistance & $1 \Omega$ & -- \\
\hline Arm inductance & $50 \mathrm{mH}$ & -- \\
\hline Capacitance per SM & $8 \mathrm{mF}$ & -- \\
\hline $\begin{array}{l}\text { Number of submodules } \\
\text { per arm }\end{array}$ & 500 & -- \\
\hline Equivalent capacitance & $16 \mu \mathrm{F}$ & -- \\
\hline DC smoothing reactor & -- & $0.5968 \mathrm{H}$ \\
\hline
\end{tabular}

Fig. 6 shows the power on each of the three parts of the system: the MMC side, the dc-dc converter and the LCC side. It is observed from Fig. 6a that the power is constant in $\mathrm{MCC}_{2}$ because that terminal controls power, while $\mathrm{MMC}_{1}$ controls the $\mathrm{dc}$ voltage and is subject to the F2F power variation. The power flow direction is changed on the MMC link at $5.5 \mathrm{~s}$, from 600 MW to $-600 \mathrm{MW}$, taking the dc input as positive for power convention. Fig. $6 c$, shows the power variation on the LCC line starting with $800 \mathrm{MW}$ from $\mathrm{LCC}_{1}$ to $\mathrm{LCC}_{2}$ and around $7.2 \mathrm{~s}$ the power flow direction is reversed. The voltage polarity variation can be observed in Fig. 6d. In this case, the roles of each LCC station are switched, such that $\mathrm{LCC}_{1}$ was initially operating as power control and $\mathrm{LCC}_{2}$ as dc voltage control (inverter). Then, after the voltage reversal, $\mathrm{LCC}_{1}$ controls dc voltage (inverter) and $\mathrm{LCC}_{2}$ controls power. Fig. $6 \mathrm{~b}$ shows, the power flow

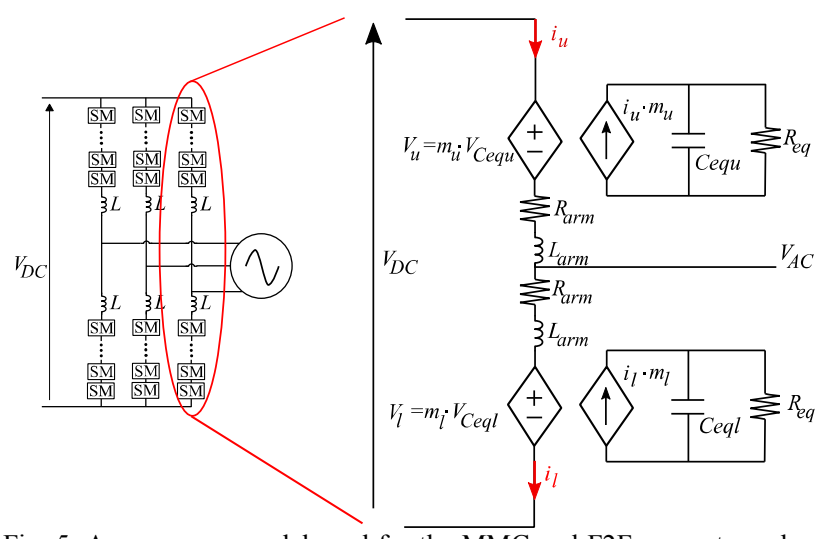

Fig. 5. Arm average model used for the MMC and F2F converter, where $\mathrm{m}_{\mathrm{u}}$ and $\mathrm{m}_{\mathrm{l}}$ are the modulation indexes.

through the F2F, where two sequences of positive-negative power between the HVDC links are tested. The first sequence at $3 \mathrm{~s}$ and the second at $8 \mathrm{~s}$, after the power reversal in both sides.

The simulations demonstrate the feasibility of the F2F to interconnect HVDC links with different technologies, topology and/or voltage ratio, in normal operation, Further studies are needed for contingencies and the evaluation of the impact of the converter on the dc grid (control strategy, losses, stability, etc.).

The use of a transformer can isolate both dc sides avoiding undesired disturbances, but it is also the main constraint for the installation of a F2F in certain applications as the offshore dc grid. The transformer increases the space usage and the weight of the converter i.e. it increases the total installation cost. A first solution would be to increase the transformer frequency, decreasing its volume, but the implications are still subject of study. A second option is the study of new topologies without the use of an ac transformer as shown in [22]. Further work must be done to evaluate the need and possible requirements of the transformer in a dc-dc converter.

\section{CONCLUSION}

The present and future European transmission grid includes the use of HVDC transmission lines, most of them for offshore applications. The growing number of HVDC links has opened the discussion about a possible, future dc grid. This paper presented the possibility to interconnect two or more existing HVDC links as a starting point for the development of $\mathrm{dc}$ multiterminal systems.

The suggested interconnections need the installation of a dc-dc converter to adapt, at least, the voltage, the HVDC technology and/or grounding topology. Among these three requirements, the most common will be the interconnection between different grounding topologies as the grounding depends on the needs of each project and it is difficult to standardize. The interconnection of different technologies can be a requirement by even distribution number of LCC and VSC links in Europe. Finally, the voltage ratio will not represent a limitation for the dc-dc converter as, most of the HVDC links in Europe have similar operating voltages, leading to a small voltage ratio transformation. 


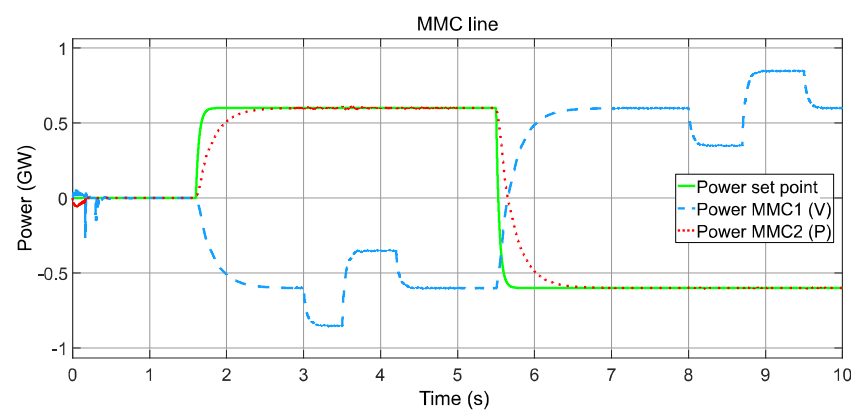

(a)

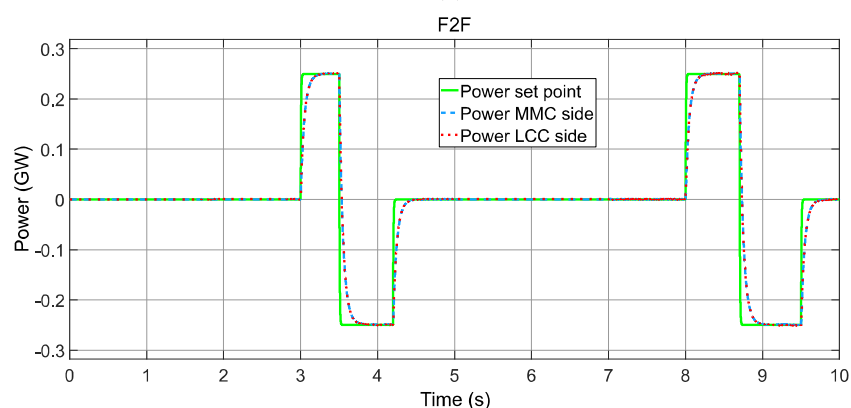

(b)

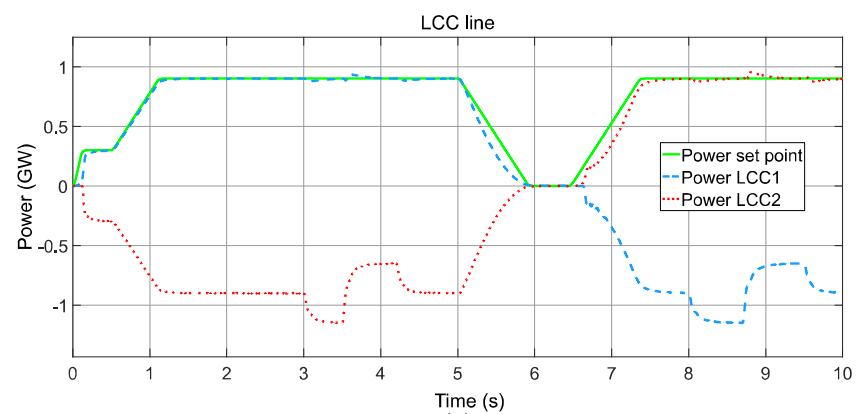

(c)

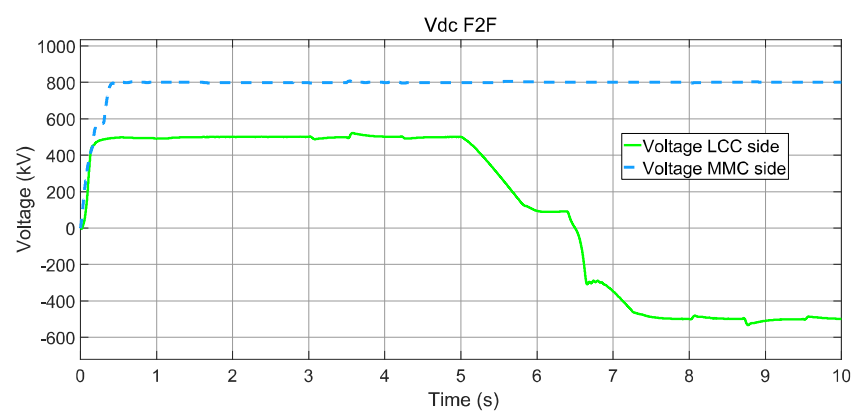

(d)

Fig.6. Simulations results for the interconnections between MMC link and a LCC link using a F2F as dc-dc converter: (a) Power on each MMC station, (b) Power transfer through the F2F (positive from LCC to MMC side), (c) Power in each LCC station, (d) voltages on both lines measured from the F2F converter.

Section IV, presents the simulation results for the interconnection between a LCC and a VSC (MMC) link. The need of FBSM, on the LCC side of the dc-dc converter, is mandatory for the power reversal (voltage polarity change) if a specialized switchgear is not used. For LCC with unidirectional power flow the FBSM are necessary only if the dc-dc converter control strategy is affected by the impact of the dc faults on LCC side leading to instability.

The need of galvanic isolation is recommended for most of the dc-dc converter applications, but it leads to higher cost and volumes, especially critical in offshore applications, which represent the majority in Europe. Further studies must be done to evaluate the alternatives of the dc-dc converter without ac transformer that fulfil the system requirements (stability, reliability, fault blocking capability, power management, security, etc.). The impact of the dc-dc converter on the grid control strategy, the response in contingencies and system reconfigurations are left for future research studies.

\section{ACKNOWLEDGMENT}

This work has been supported by a grant overseen by the French National Research Agency (ANR) as part of the "Investissements d'Avenir" Program (ANE-ITE-002-01).

\section{REFERENCES}

[1] H. Wang and M. A. Redfern, "The advantages and disadvantages of using HVDC to interconnect AC networks," in 45th International Universities Power Engineering Conference UPEC2010, 2010, pp. 15 .

E. Oni, I. E. Davidson, and K. N. Mbangula, "A review of LCCHVDC and VSC-HVDC technologies and applications," in 2016 IEEE 16th International Conference on Environment and Electrical Engineering (EEEIC), 2016, pp. 1-7.

[3] Simplemaps, "SGV world map." Simplemaps, 2017 [Online]. Available: https://simplemaps.com/resources/svg-world. [Accessed: May 3, 2019].

[4] CIGRE WG. B4.52, "HVDC Grid Feasibility Study." CIGRE, Apr2013 [Online]. Available: https://e-cigre.org/publication/533-hvdcgrid-feasibility-study. [Accessed: July 3, 2018].

[5] D. Jovcic, D. van Hertem, K. Linden, J. Taisne, and W. Grieshaber, "Feasibility of DC transmission networks," in 2011 2nd IEEE PES International Conference and Exhibition on Innovative Smart Grid Technologies, 2011, pp. 1-8.

[6] C. D. Barker, C. C. Davidson, D. R. Trainer, and R. S. Whitehouse, "Requirements of DC-DC Converters to facilitate large DC Grids." CIGRE and Alstom Grid UK Ltd, 2012 [Online]. Available: https://ecigre.org/publication/B4-204 2012-requirements-of-dc-dc-

converters-to-facilitate-large-dc-grids. [Accessed: July 3, 2018].

[7] G. P. Adam, I. A. Gowaid, S. J. Finney, D. Holliday, and B. W. Williams, "Review of DC-DC converters for multi-terminal HVDC transmission networks," IET Power Electronics, vol. 9, no. 2, pp. 281296, 2016.

[8] ENTSO-E, “ENTSO-E Transmission System Map." ENTSO-E [Online]. Available: https://www.entsoe.eu/data/map/. [Accessed: Jan. 25, 2019].

[9] European Commission, "ENERGY Projects of common interest Interactive map." PLATTS for the underlying grids for electricity, gas and oil, 2018; European Union, 2018 [Online]. Available: http://ec.europa.eu/energy/infrastructure/transparency_platform/mapviewer/main.html\#\&ui-state=dialog. [Accessed: Feb. 25, 2019].

[10] ENTSO-E, "TYNDP 2018 - Project Sheets." ENTSO-E [Online]. Available: https://tyndp.entsoe.eu/tyndp2018/projects/. [Accessed: Jan. 25, 2019].

[11] M. Barnes and T. Heath, "VSC-HVDC Newsletter." School of Electrical \& Electronic Engineering, University of Manchester, Apr2019.

[12] P. E. Ms. Robyn L. Koropatnick, "HVDC Projects Listing." HVDC and Flexible AC Transmission Subcommittee of the IEEE Transmission and Distribution Committee [Online]. Available: http://www.ece.uidaho.edu/hvdcfacts/Projects/HVDCProjectsListing March2012-existing.pdf. [Accessed: Apr. 20, 2019].

[13] J. G. Dedecca, R. A. Hakvoort, and P. M. Herder, "The integrated offshore grid in Europe: Exploring challenges for regional energy 
governance," Energy Research \& Social Science, vol. 52, pp. 55-67, 2019.

[14] P. Bhagwat et al., "D7.4 Economic framework for a meshed offshore grid," PROMOTioN project, 2019 [Online]. Available: https://www.promotion-

offshore.net/fileadmin/PDFs/D7.4_Economic_framework_for_a_mes hed offshore grid.pdf. [Accessed: Jun. 03, 2019].

[15] A. L'Abbate, R. Calisti, and S. Rossi, "Development of HVDC offshore grids in the European system: long-term transmission expansion analyses," in 15th IET International Conference on AC and DC Power Transmission (ACDC 2019), 2019, pp. 1-6.

[16] ENTSO-E, "2nd ENTSO-E Guideline For Cost Beneft Analysis of Grid Development Projects FINAL -Approved by the European Commission." ENTSO-E, Sep-2018 [Online]. Available: https://tyndp.entsoe.eu/Documents/TYNDP\%20documents/Cost $\% 20$ Benefit\%20Analysis/2018-10-11-tyndp-cba-20.pdf. [Accessed: Dec. $12,2018]$.

[17] M. Heggås and R. Bakken, "A review of condition assessment methods for high voltage subsea power cables," Norwegian University of Science and Technology, 2018 [Online]. Available: https://www.researchgate.net/publication/330467510_A_review_of_c ondition_assessment_methods_for_high_voltage_subsea_power_cabl es. [Accessed: Jan. 25, 2019].

[18] T. Worzyk, Submarine power cables: design, installation, repair, environmental aspects. Springer Science \& Business Media, 2009.

[19] ENTSO-E, "Project 335 - North Sea Wind Power Hub." ENTSO-E [Online]. Available: https://tyndp.entsoe.eu/tyndp2018/projects/projects/335. [Accessed: Jan. 25, 2019].

[20] North Sea Wind Power Hub, "North Sea Wind Power Hub - Planning the Future Today." Northseawindpowerhub, 2019 [Online]. Available: https://northseawindpowerhub.eu/. [Accessed: Apr. 30, 2019].

[21] C. Hirsching, M. Goertz, S. Wenig, S. Beckler, M. Suriyah, and T. Leibfried, "On control and balancing of MMC-HVdc links in rigid bipolar configuration," in 15th IET International Conference on AC and DC Power Transmission (ACDC 2019), 2019, pp. 1-6.

[22] G. J. Kish, "On the emerging class of non-isolated modular multilevel DC-DC converters for DC and hybrid AC-DC systems," IEEE Transactions on Smart Grid, 2017.

[23] J. D. Páez, D. Frey, J. Maneiro, S. Bacha, and P. Dworakowski, "Overview of DC-DC Converters Dedicated to HVdc Grids," IEEE Transactions on Power Delivery, vol. 34, no. 1, pp. 119-128, Feb. 2019.
[24] A. Schön and M. Bakran, "High power HVDC-DC converters for the interconnection of HVDC lines with different line topologies," in 2014 International Power Electronics Conference (IPEC-Hiroshima 2014 ECCE ASIA), 2014, pp. 3255-3262.

[25] B. Paths, "Best Paths, Transmission for sustainability." Best Paths [Online]. Available: http://www.bestpaths-project.eu/. [Accessed: Feb. 25, 2019].

[26] M. Szechtman, "First benchmark model for HVDC control studies," Electra, vol. 135, pp. 55-73, 1991.

[27] J. Freytes, L. Papangelis, H. Saad, P. Rault, T. Van Cutsem, and X Guillaud, "On the modeling of MMC for use in large scale dynamic simulations," in 2016 Power Systems Computation Conference (PSCC), 2016, pp. 1-7.

[28] F. Xinkai, Z. Baohui, and W. Yanting, "Fast electromagnetic transient simulation models of full-bridge modular multilevel converter," in 2016 IEEE PES Asia-Pacific Power and Energy Engineering Conference (APPEEC), 2016, pp. 998-1002.

[29] J. D. Páez, J. Maneiro, D. Frey, S. Bacha, A. Bertinato, and P. Dworakowski, "Study of the impact of DC-DC converters on the protection strategy of HVDC grids," in 15th IET International Conference on AC and DC Power Transmission (ACDC 2019), 2019, pp. 1-6.

[30] K. Shinoda, J. Freytes, A. Benchaib, J. Dai, H. Saad, and X. Guillaud, "Energy difference controllers for MMC without DC current perturbations," in The 2nd International Conference on HVDC (HVDC2016), 2016.

[31] A. Zama, A. Benchaib, S. Bacha, D. Frey, and S. Silvant, "High dynamics control for MMC based on exact discrete-time model with experimental validation," IEEE Transactions on Power Delivery, vol. 33, no. 1, pp. 477-488, 2017.

[32] D. Jovcic and $\mathrm{K}$. Ahmed, High voltage direct current transmission: converters, systems and DC grids. John Wiley \& Sons, 2015.

[33] ALSTOM Grid, "HVDC for beginners and beyond." 2010 [Online]. Available:

http://cigre.ru/research commitets/ik rus/b4 rus/library/ALSTOM HVDC_for_Beginners_and_Beyond.p̄df. [Äccessed: March 23, 2018].

[34] S. Lu, W. Lin, J. Wen, L. Yao, and Z. Wang, "Power flow control of interconnecting two LCCHVDC through front-to-front type DC/DC converter," in 2016 IEEE 8th International Power Electronics and Motion Control Conference (IPEMC-ECCE Asia), 2016, pp. 26222626. 